\title{
Evaluation as an Opportunity for Reflection: Stakeholder View of Teacher Performance
}

\begin{tabular}{|c|c|}
\hline \multicolumn{2}{|c|}{$\begin{array}{c}\text { Hasan TABAK* } \\
\text { Department of Educational Sciences, Aksaray University, Aksaray, Turkey } \\
\text { hasantabak@aksaray.edu.tr https://orcid.org/0000-0003-3923-5133 }\end{array}$} \\
\hline Article history & This study aimed to determine opinion of the parties who are responsible \\
\hline Received: & for the teacher performance evaluation process in private schools. \\
\hline 13.12.2019 & \\
\hline $\begin{array}{l}\text { Received in revised form: } \\
25.01 .2020\end{array}$ & $\begin{array}{l}\text { private schools, this study was a qualitative type using the } \\
\text { phenomenographic model. The study group consisted of a total of } 20 \\
\text { individuals including school principals, vice-principals, group leaders }\end{array}$ \\
\hline $\begin{array}{l}\text { Accepted: } \\
05.02 .2020\end{array}$ & $\begin{array}{l}\text { who are responsible for teacher performance evaluation, and teachers } \\
\text { whose performance was evaluated. The interviews were conducted using }\end{array}$ \\
\hline Key words: & semi-structured interview questions. The face-to-face interview protocol \\
\hline $\begin{array}{l}\text { Teacher performance } \\
\text { evaluation, Responsible } \\
\text { stakeholder in performance } \\
\text { evaluation, School principals }\end{array}$ & $\begin{array}{l}\text { was applied during the planning of the data collection process. The } \\
\text { content analysis method was resorted to analyze the data obtained in the } \\
\text { study. The fact that this study consulted not only teachers or school } \\
\text { management but also all stakeholders responsible for TP shows that the } \\
\text { study has considerable strength. In qualitative analysis, analyzing the } \\
\text { views according to the theoretical framework can sometimes be difficult. } \\
\text { As laid out by the results of the study, the views are centered on the } \\
\text { "effect" theme of the teacher performance evaluation process. The study } \\
\text { concluded that, the teachers encountered the possibility of understanding } \\
\text { their qualifications as a teacher by turning the teacher performance } \\
\text { evaluation process into an opportunity. }\end{array}$ \\
\hline
\end{tabular}

\section{Introduction}

Teacher performance (TP) may vary according to the control in the classroom environment and unpredictable variables. However, the use of a measurement process may grant teachers who to seek to become better teachers at the end of that process an opportunity (Ross, Singer-Dudek \& Greer, 2005). Teachers' self-regulation processes, including selfmonitoring and self-assessment, guide students' learning, boost teachers' performance, and improve their inclinations regarding the planning of teaching (Kitsantas \& Baylor, 2001). Teachers see the objective of the ideal teacher assessment as either professional development or an inspiration to think about their teaching practices (Peterson \& Comeaux, 1990).

\section{What is the objective of teacher performance evaluation (TPE)?}

The idea that student learning is well-measured by a particular test and that this provides information about a teacher's performance assuming it is influenced only by the teacher and is independent of the growth of classmates or any other aspects of class content. In other words,

\footnotetext{
*Correspondence: hasantabak@aksaray.edu.tr
} 
teacher assessment is based on the belief that the achievement level measured for a particular teacher's students reflects that teacher's "efficiency" (Darling-Hammond, Amrein-Beardsley, Haertel \& Rothstein, 2012). According to the results of the research carried out by Loup, Garland, Ellett, and Rugutt (1996) on teachers, the leading objectives of teacher performance evaluation (TPE) were shown to be accountability, professional development, personal decisions, and instructional leadership. Research findings focusing on teachers of poorly performing schools show that administrators tend to give positive scores to teachers who are likely to lose their jobs due to the result of the performance evaluation (Qi, Bell, Jones, Lewis, Witherspoon \& Redash, 2018). Half of the teachers whose performances were evaluated stated that the test data showing student achievement, which was among the assessment criteria, was not an accurate measure of students' learning (Darling-Hammond, 2015). In addition, the evaluation of performance obviously requires considerable training on assessment. It requires demounting each teacher's performance and then integrating the pieces into a whole in order to relate them to the dimensions required for teacher competence (Davey, 1991).

The success or failure of evaluation and incentive systems in schools are linked to the following factors: (1) Quality of implementation: management was complex and that the local government prevented the implementation of fair measurements. Furthermore, capacity building around new measurements was very limited. (2) The expectation of rewarding: it was difficult for teachers to link monetary rewards to effort and performance. (3) Openness, procedural, or distributive justice: evaluations were considered low in all these processes (Mintrop, Ordenes, Coghlan, Pryor \& Madero, 2018). Students constitute solely one group of stakeholders in TPE, and their opinions are among the many criteria. However, obtaining information alongside a multilateral evaluation of TP from students is scientifically recommended (Peterson \& Stevens, 1988). Another stakeholder in TPE is parents. Although they are not the direct internal shareholders of the process, parents can contribute to multilateral evaluation by providing data (Peterson, 1989). In their research, as a result of the feedback they received during teacher evaluation, Tuytens and Devos (2014) aimed to use a model to test a set of three variables (e.g., procedural, leadership, and teacher variables) that could affect teachers' professional learning activities. Leadership was determined to be the most effective variable in measuring TP. Therefore, leadership behaviors were concluded to have a positive effect on performance. As a result of peer evaluation among teachers in TPE, an improvement plan can be put into effect. If teachers need assistance for improvement, this assistance should be provided for them (Wilson \& Wood, 1996). Themes used in this study (Herbert and Mcnergney, 1989)- (1) evaluation system design: TPE should be a system that argues. It includes evaluators' objective and in-depth devices in the system. (2) process functioning: this emphasizes an effective process by minimizing the problems to be encountered in the assessment process. These reasons are considered in the continuation of the system design, the quality of the process and the restrictions pertaining to the feedback received and (3) effect: this expresses the result of feedback or evaluation as part of the system. In this way, interested parties should take into account the degree of impact and also should take the necessary action.

\section{Can TP be standardized?}

The use of standardized test scores to evaluate teachers includes various unpredictable elements as well as the provision of an educational accountability policy as an output indicator of the education system (Briggs \& Domingue, 2011). Within the tradition of psychological research, the complex forms of human performance are assumed to be understood in terms of the operation of the underlying general processes. Therefore, it seems rather impossible to say that TP can be fully measured using standard data collection tools thinking that these general 
forms of teaching behaviour are associated with student performance (Shulman, 1987). New assessments are needed to tell whether teacher education graduates have developed the classroom teaching skills to be effective with their students because current teacher tests do not directly measure what teachers do in the classroom, and they do not indicate how well teachers will do in the classroom (Darling-Hammond, 2010; Peck, Gallucci \& Sloan, 2010). In a study conducted by Donaldson and Woulfin (2018), 44\% of the principals who were primarily responsible for TPE stated that the lack of assessment standards and policies made it difficult to establish TP. Ellett, Wren, Callender, Loup, and Liu (1996) tried to develop a standard for TPE in their research. According to this research, TP was made up of some components such as (1) propriety, (2) utility, (3) feasibility, and (4) accuracy. However, there are also a number of qualifications underlying the existing standards.

Although evaluations have various purposes, it is not always clear whether the focus is on the quality of the process or on the standard of the outcome. Differentiating questions such as "Is it the learning process or the standard of what is learned?" or "Should it be the quality and management of the learning environment or the achievement of the predefined service standards?" may help us concentrate upon what is to be evaluated (Harvey, 2002). The governmentality of high-stakes testing has been employed to define student achievement and teacher readiness in narrow positivistic ways that severely limit what can be said in discussions regarding educational quality and impact (Coloma, 2015). Criteria for evaluating the teaching task should be weighted to reflect the relative importance of different aspects of the job. For example, if interacting with parents involves approximately $10 \%$ of the teacher's responsibilities, 4 items on a 40 -item scale should evaluate teachers' level of assurance in this area. In interaction with parents, trust can be weighted differently at the primary, intermediary, and secondary levels. As the tasks at these levels vary considerably, separate measures may be required for each of these levels (Tschannen-Moran, Hoy \& Hoy, 1998). Observation-based performance evaluation systems among teachers are often difficult to implement. When making observational assessments of teachers, school administrators should pay attention to trends in widget impacts, such as seeking the cause of low performance initially within the environment itself rather than doing so related to the teacher first (Cohen \& Goldhaber, 2016).

In fact the priority in measuring TP is to adjust teaching standards according to these objectives. The National Board for Professional Teaching Standards in the USA has established specific criteria for how successful teachers can apply the type of learning required by student learning standards in 1987. Similarly, the New Teacher Assessment and Support Consortium has developed modelling standards for teachers accepted by more than 40 states. The best promise for significantly improving education at all levels of the system is for educators to assume accountability and make it useful for learning and improvement (Darling-Hammond, 2012). In their study, Herbert and Mcnergney (1989) concluded that (1) the personnel evaluation system was effective in terms of process functionality, (2) the system had to be appropriate for the design of the education system, and (3) the clinical evaluation system had the desired effects. In this context, effective evaluation of teacher performance is basically a difficult issue. Serious budgeting as well as a fair number of human resources are required to evaluate the teacher in the education system through a multiple number of data sources within a period for the teacher performance indicators to be standardized. What is more, it is difficult to determine what "good performance" stands for. One might think that this can be addressed referring to standardized measuring tools and a measuring system. Although this idea seems rational in terms of the cost of TPE, the relevant literature shows that it indeed is insufficient to measure its effectiveness. 


\section{Responsible Parties in TP}

The leading factors affecting teacher self-assessment are teacher peer review and the evaluations of superintendents and school board members. Thusly a need arises for studies examining teacher evaluation by students. The main objective of this evaluation is not only to identify strong or weak teachers, but also to ensure teacher development (Epstein, 1985). Teachers can gain information from evaluation and subsequently develop new skills, increase long-run effort, or do both of these (Taylor \& Tyler, 2012).

The teacher evaluation model confirms the principal's superiority as an evaluator/expert and strengthens the management-work distinction between principals and teachers, respectively. As the research results clearly lay out, the presence of this relationship is ineffective at improving TP. The joint evaluation may prevent the interference of bias in performance and evaluation decisions (Haefele, 1992). A well-planned and systematic supervision and a performance program that provides teachers with significant opportunities targeting to improve both the quality of education and students' learning opportunities are essentially prerequisites for leaders who want to lead teachers effectively. The TPE system must be centred on teacher autonomy (Ghamrawi, 2010). In this way, it can be said that the teacher will have positive motivation and positive communication with the school administrators who have a positive school atmosphere (Şahin, Sönmez \& Yavuz Tabak, 2019). In Painter's (2000) research, TP was grouped under headings such as attitudes about the importance of dealing with low-performing teachers, principals' confidence in their skills, reasons for delays, or decisions to not pursue intensive supervision and support. The study proposed creating a performance evaluation process design by focusing on these topics. School principals rely on their evaluation knowledge and supervisory skills related to TP. In addition to saying that they perceive supervision to be more problematic than performance evaluation, principals see the support coming from others as a little less than the one coming from school board members. The data that school managers have in TPE includes features such as (1) support for the school mission, (2) instructional research focus, (3) multiple sources of data, (4) continuous process, (5) focus on student outcomes, and (6) integration with other school and district systems. This accounts for the characteristics of the evaluation system in terms of both its reliability and widespread impact (Murphy, 1987). The costs of supporting faculty and staff participation in training and scoring for a TPA are not trivial, and contemporary budget pressures have led many program administrators and policy makers to turn to an outsourcing strategy for containing these costs through cooperative agreements with commercial assessment vendors (Berlak, 2011; Peck, Singer-Gabella, Sloan \& Lin, 2014).

Schools in the Turkish Education System are divided into two as public and private schools. A long-standing debate about the non-implementation of TPE in Turkey is observed in the literature (Y1ldırım, 2013). To that end since the working group of the study covers the relevant parties of a private school, it can be mentioned that TPE is mostly applied in private schools. Basically, the coordination of the TPE human resources department in private schools is carried out by a committee consisting of the school principal, the vice principal and the group leader (Şat, 2013). In some cases, students and parents may be asked to take part in the evaluation (Hatipoğlu \& Kavas, 2016). However, there is not a common TPE system available and each school carries out a unique assessment. As a result of TPE, it is possible to dismiss the teachers whose performance are not satisfactory or to carry out the assessment in the following year again. These often lead to psychological tension for teachers.

It is notable that there is no research into TPE with a private school sampling in Turkey. However, private schools employ teachers by renewing contracts every year. They renew 
teacher contracts according to the data obtained from parents' and students' opinions; nevertheless, teachers believe that the data collection process and the data obtained do not actually fit the TPE process. In this context, this current study aimed to determine the views of responsible parties of TPE and teachers working in private schools. In this research, the qualitative views of the school principal (SP), vice-principals (VP), group leaders (GL) and teacher $(\mathrm{T})$ were taken as a stakeholder. In this context and aim, the study sought answers to the following questions:

(1) What are the views of SP, VP, GL, and T in teacher performance evaluation?

(2) What are the positive and negative perspectives of SP, VP, GL, and T on the evaluation system design, process functioning, and on the effect to explain the structures and functions related to teacher performance?

\section{Methodology}

Carried out to determine the positive and negative views of the responsible parties in TPE in private schools, this study was a qualitative type using the phenomenographic model. Phenomenographic research aims to understand people's thoughts on a particular subject indepth and systematically. The thought here is called a phenomenon. The phenomenographic research model intends to understand the phenomenon that conveys different meanings for different people (Bogdan \& Biklen, 1997; Richardson, 1999). In this study, the phenomenon is the opinions of responsible parties in TP. To obtain these opinions, a phenomenographic modelappropriate interview technique was employed.

\section{Participants}

The study group consisted of the personnel of a private school in İstanbul. The school has branches throughout Turkey, and the group consisted of school principals $(n=5)$, viceprincipals $(n=5)$, group leaders $(n=5)$, and teachers $(n=5)$. The study group was formed based on the convenience sampling method. Although this method has some limitations in terms of obtaining information and reliability, the researcher can control the group's distribution, when necessary, thanks to its flexibility (Miles \& Huberman, 1994). All of the school principals included in the study were male. However, half of the other participants were female, which ensured an equal gender distribution. Nearly half of the participants had a master's degree. Teaching experience varied between 12 and 35 years in general. In this study, the researchers aimed to reduce the impact of gender on the views on TPE by providing a wide range of teaching experiences and equality between females and males as much as possible. This is to eliminate the limitation of the sampling method. In this way, internal validity was ensured.

\section{Data Collection}

The data collection procedure consisted of interviews to determine the SP, VP, GL and $\mathrm{T}$ were taken as a stakeholder opinion of TPE. The interviews were conducted using semistructured interview questions. Some basic steps were followed in the development of the semistructured interview form. The first of these steps was the obtaining of the opinions of two field experts: one expert from the measurement and evaluation field and one language expert who focused on the eight interview questions, which were created following a review of the related literature and legal basis. The interview form, designed in accordance with expert opinions, was piloted to three teachers who were not included in the study group. Based on the evaluations of the field experts and the measurement and evaluation expert, only three main questions were 
asked on the grounds that some items could become repetitive and some might try to measure the same things using different expressions. Accordingly, the final set of questions were as follows: From the perspective of the school principal, vice-principal, group leader, and teacher in private schools, (1) What are the positive sides of TPE? (2) What are the negative sides of TPE? (3) What are your suggestions for a better evaluation process? Can you also give your reasons for each answer?

The face-to-face interview protocol was applied during the planning of the data collection process. This protocol is a set of practical procedures that ensure the data collection process is valid and reliable (Saldaña, 2015). Following the rules of the protocol, the interviews were partly spread out over time due to the interviewees' positions and the intensity of their workloads, which varied according to their positions. Thus, each interviewee was asked to determine alternative appointment dates for the interview. To that end, the participants determined an alternative interview schedule by taking their workloads into account and informing the researcher about the change. The interviews took place in an atmosphere where the participants could express themselves freely, and at a time that was appropriate for them. Each interview lasted between 15 and 28 minutes on average. To protect the participants' privacy, they were informed that their personal information would not be used within the scope of the study. All these procedures helped to conveniently fulfill the face-to-face interview protocol rules.

\section{Data Analysis Procedures}

The content analysis method was employed to analyze the data obtained in the study. The basic process followed in content analysis is to bring together similar data within the framework of certain concepts and themes and then interpret the data in a way that readers can understand. With this aim, the data analysis comprised the following stages: (a) Transferring interview data into a computer file, (b) Creating themes according to the relevant literature, and (c) Identifying and organizing codes (Mason, 2002; Yıldırım \& Şimşek, 2008). The themes were created according to Herbert and Mcnergney's (1989) TPE process classification. Accordingly, the themes were (1) evaluation system design, (2) process functioning, and (3) effect. No direct information about the participants was given. In referring to the opinions of the participants in the analysis section, abbreviations such as SP1, SP2 for the school principal, VP1, VP2 for the vice-principal, GL1, GL2 for the group leader, and T1, T2 for the teacher were used.

While presenting direct quotations, code names consisting of the participants' quotations were made use of. To provide neutrality and reliability in determining these codes, the analyst diversity technique can be used by asking different researchers to create independent codes (Creswell, 2002). In this study, two different researchers carried out content analysis and classified the themes and codes. Each researcher analyzed the data obtained one by one. The internal consistency coefficient of the codes generated by the analyst diversity technique was .83. This coefficient indicates a high level of consistency between the coders (Krippendorff, 2004).

\section{Interview Findings}

Qualitative findings were presented according to the sub-problem questions of the study. First, the themes, codes, and participant distributions obtained as a result of the interviews with the participants were presented. Following this step, content analysis results were structured based on the themes. Finally, the positive and negative overview of the TPE 
classification was presented. The findings of the study were structured according to Herbert and Mcnergney's (1989) TPE's (1) system design, (2) process functioning, and (3) effect classification. In general, in-depth analysis of the views of stakeholders viz. P, VP, GL and T under these themes yielded codes: (1) system design: school recognition; improving student achievement; stakeholder opinion; (2) process functioning: setting criteria; assortment of evaluators; emotional behavior; power battle; biased evaluation; (3) effect: feedback; getting to know the teacher; increasing motivation; organizational belonging; business anxiety; anxiety of satisfaction (see figure 1).
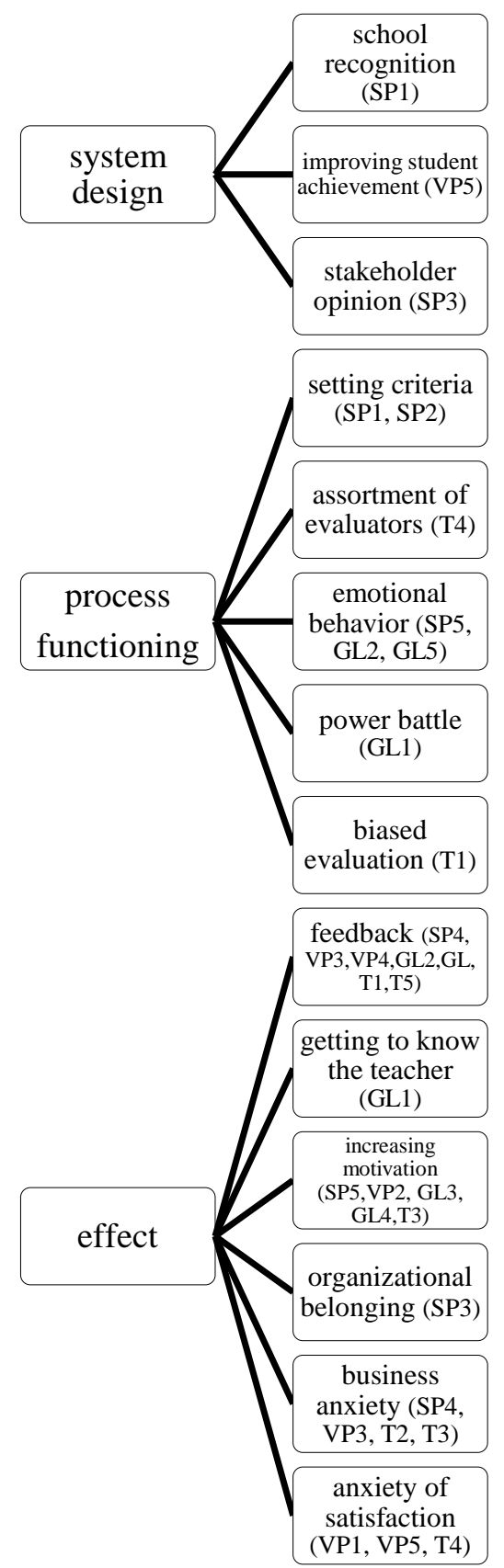

SP: school principal

VP: vice-principal

GL: group leader

$\mathrm{T}$ : teacher

Figure 1. Teacher performance evaluation themes, codes, and distribution of participants 


\section{Theme I: System design}

School principals and vice-principals expressed their opinions under this theme. School principals stated that student and parent satisfaction was usually effective on TP. "Therefore, this satisfaction can be achieved with the teacher. The most important stakeholder for a private school is the teacher," they added. On the other hand, VP5 said, "when we evaluate the performances, this positively contributes to the increase in student productivity, because a teacher who devotes all his energy to his students will have a positive effect on the institution." However, SP3 stated that the collecting of related stakeholders' views on TPE did not reflect the reality in some cases and pointed out the importance of using multilateral data sources during performance evaluation. This view is quoted below.

SP3: "Sometimes students and parents are dominant. We should not accept the feedback coming from each parent and each student evaluate[s] a teacher's actual performance."

\section{Theme II: Process Functioning}

It was witnessed that participants emphasized the functioning of the TPE process as an important issue. One of the important codes of this theme was setting the evaluation criteria. Although teachers were expected to behave sensitively in this issue, because they are the ones who were being evaluated, the opinions came from SPs. For example, SP2 said, "I think it is a good idea to give the criteria to the teachers before the evaluation process. If it is postponed, the teacher can feel anxious and therefore cannot plan the process." Contrary to this view, SP1 expressed the opinion that setting the criteria might bring about negative consequences, and said, "If performance evaluation cannot be made objectively and if the criteria are not healthy, the process may move away from rightness. This is entirely related to the criteria used."

Unlike school principals, the group leaders mentioned that performance was subjected to positive or negative ratings by the exhibition of emotional attitudes in TPE. Similarly, a school principal emphasized that personal problems were included in the evaluation process and that this led to undesirable evaluation results.

GL2: "Sometimes there may be problems between the group leader and the teacher. Personal feelings can interfere with their business. The group leader and the teacher can sometimes have problems as they always work together."

SP5: "Group leaders, vice-principals, etc., may reflect their personal problems in this evaluation because sometimes teachers who tell the truth can be found unlovely."

One of the negative views was that a TP without a specific criterion could mean biased evaluations or evaluations that lacked evidence. For instance, supporting this view, GL1 said, "Gossip may be one of the negative cases. Conflicts and power battles begin among teachers. A chaotic atmosphere can emerge." On the other hand, teachers' views indicated a positive overview. They stated that TPE provided genuine feedback. Indeed, T1 emphasized the feedback function by saying, "People can see their mistakes when performance is evaluated. Without assessment, teachers cannot see their deficiencies or cannot mend them."

\section{Theme III: Effect}

It is noteworthy that, in general, participants" views centered on the "effect" theme, which constitutes the output or outcome dimension of the evaluation process. As a negative overview, there were opinions under the code of business anxiety, which was an expected result, as this study had a private school sample. Due to the fact that contracts in private schools are 
renewed once a year based on TP, the teachers indicated that the existence of explicit evaluations and objective treatment created a good situation for the teachers; otherwise, they mentioned the likelihood of being unemployed. To illustrate, T3 said, "When they see me working and give me positive feedback on this, it improves my performance. Getting the return of my labor spiritually and materially provides me with the enthusiasm for the next year." Thus, T3 confirmed the aforementioned implication. Additionally, SP3 expressed their opinion that high performance should be rewarded apart from positive feedback as a result of TPE by saying, "If we reward positive performance, this promotes the sense of organizational belonging of the teacher. As a result, we see that this is a 10-year-old institution, and some teachers have been here for 10 years." With this opinion, SP3 stated that rewarded high performance increased a teacher's desire to work in the school and developed a sense of organizational belonging.

One of the common views of SP, VP, GL, and T with respect to TPE was that it helped with conveying the necessary feedback. In particular, the teachers stated that the parties responsible for the assessment could support the teacher by warning him or her and providing a chance for the teacher to correct deficiencies before the evaluation was conducted. The following quotations lay the groundwork for the idea of helping in a way that supports the teacher without overrating any deficiencies.

T1: When performances are evaluated, people can see their own mistakes. Without assessment, teachers cannot discover self-deficiencies and cannot work on correcting these.

Vice-principals, who provide the coordination between the school principal, the group leader, and teachers, positively evaluated the performance evaluation. VP2 stated that a teacher who knows that he or she will be evaluated exhibits a greater willingness in working by saying, "Sometimes they are not aware, but they are doing things that will end up with a really good result and create an impact, and I think it's a positive thing in terms of raising awareness here. In other words, when we evaluate their performance positively, I see that their motivation also increases. Furthermore, if the evaluation system is effective, the overall work motivation is positively affected, as they know they will receive feedback."

\section{General Overview: Thematic approach to TPE}

SPs, VPs, GLs, and Ts interviewed apparently have mostly a positive overview of TPE. In other words, opinions showing the necessity of TPE were included under various codes. However, there were differences in the distributions of the views in TPE themes. The first fundamental difference was that the participants focused mostly on the theme of "effect" in performance evaluation. This shows that the participants focused on the results of performance evaluation. The examination of the participants' views indicated that the factor of staying in the job or continuing to work usually led to negative emotions in teachers.

In the general overview, there were views about the process functioning and system design themes, respectively. In addition, almost half of the participants expressed negative views about TPE. When negative opinions were examined, they appear in codes as stakeholder opinion, setting criteria, emotional behavior, power battle, biased evaluation, business anxiety, and anxiety of satisfaction. In the emotional behavior code, located in the negative overview category, the biased evaluation code came to the fore on the grounds that the evaluators evaluated teachers with irrelevant criteria during performance evaluation. Also, the anxiety of satisfaction frequently came into play in cases in which the mutual expectations of teachers, students, parents, and school administrators were not met. Finally, it would be fair to state that 
the majority of the views were expressed about the "feedback" code of performance evaluation.

Table1. Overview of participants' TP assessment themes

\begin{tabular}{|c|c|c|c|c|c|c|c|c|c|c|c|c|c|c|c|}
\hline & \multicolumn{3}{|c|}{$\begin{array}{l}\text { System } \\
\text { design }\end{array}$} & \multicolumn{5}{|c|}{ Process functioning } & \multicolumn{7}{|c|}{ Effect } \\
\hline & 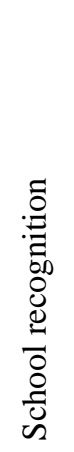 & 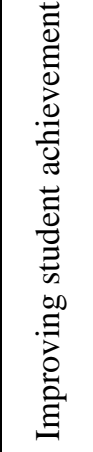 & 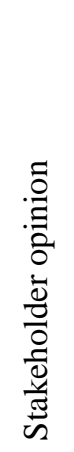 & 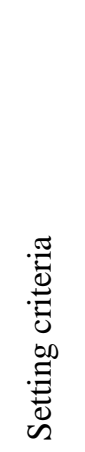 & 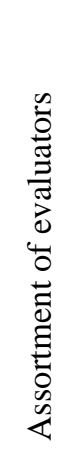 & 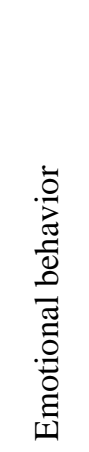 & 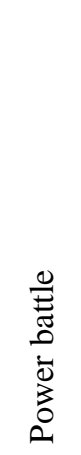 & 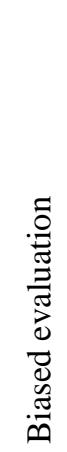 & 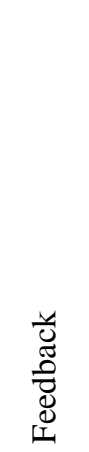 & 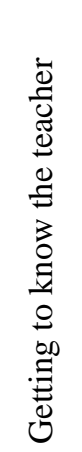 & 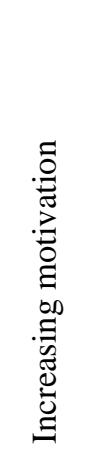 & 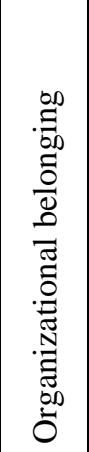 & 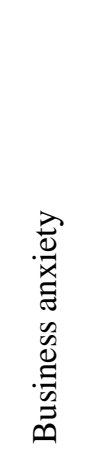 & 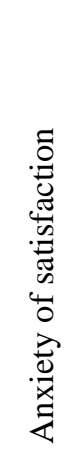 & 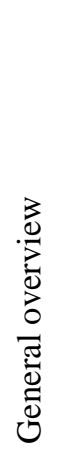 \\
\hline $\begin{array}{l}\text { Positive } \\
\text { overview }\end{array}$ & SP1 & VP5 & -- & SP2, & $\mathrm{T} 4$ & -- & -- & -- & $\begin{array}{l}\text { T1, } \\
\text { GL2, } \\
\text { T2, } \\
\text { VP3, } \\
\text { SP4, } \\
\text { VP4, } \\
\text { GL5, } \\
\text { T5 }\end{array}$ & GL1 & $\begin{array}{l}\text { VP2, } \\
\text { GL3, } \\
\text { T3, } \\
\text { GL4, } \\
\text { SP5 }\end{array}$ & SP3 & -- & -- & 19 \\
\hline $\begin{array}{l}\text { Negative } \\
\text { overview }\end{array}$ & -- & -- & SP3 & SP1, & -- & $\begin{array}{l}\text { GL2, } \\
\text { SP5, } \\
\text { GL5 }\end{array}$ & GL1 & $\mathrm{T} 1$ & -- & -- & -- & $\mid--$ & $\begin{array}{l}\text { T2, } \\
\text { VP3, } \\
\text { T3, } \\
\text { SP4 }\end{array}$ & $\begin{array}{l}\text { VP1, } \\
\text { T4, } \\
\text { VP5 }\end{array}$ & 14 \\
\hline $\begin{array}{l}\text { General } \\
\text { overview }\end{array}$ & \multicolumn{3}{|c|}{$\begin{array}{c}\text { System } \\
\text { design } \\
(f: 3)\end{array}$} & \multicolumn{5}{|c|}{$\begin{array}{l}\text { Process functioning } \\
\qquad(f: 8)\end{array}$} & \multicolumn{7}{|c|}{$\begin{array}{l}\text { effect } \\
(f: 22)\end{array}$} \\
\hline
\end{tabular}

\section{Results and Discussion}

The results of the research were discussed in line with the findings. According to the results of the research, the views were found to center on the "effect" theme of the TPE process. This may be related to the feedback function of TP (Cohen \& Goldhaber, 2016; Ellett, Wren, Callender, Loup \& Liu, 1996; Harvey, 2002; Milanowski \& Heneman, 2001; Mintrop, Ordenes, Coghlan, Pryor \& Madero, 2018). At the end of the process, teachers have the potential to understand their qualifications as a teacher by turning the TPE process into an opportunity and to amend their negative features through an effective evaluation system. It is frequently emphasized that TPE should not be seen as a simple evaluation function for it is basically a process (Peterson \& Stevens, 1988; Richardson, 1999; Tschannen-Moran, Hoy \& Hoy, 1998; Wilson \& Wood, 1996). However, it is worth emphasizing that teachers were stressed and that they experienced business anxiety at the end of the TPE process. Another finding of this study is that group leaders, who are the critical stakeholders of this process, play a key role in alleviating the emotional burden of TPE.

\section{Theme I: System design}

The opinions of the participants, who saw the TPE process as a system involving inputprocess and output, indicated that the obtaining of the views of the stakeholders in TPE sometimes did not reflect the reality and, therefore, that using multilateral data sources to evaluate the performance was of utmost importance. Thus, the study findings, in this sense, 
showed similarities with the view in the literature that joint evaluation can prevent the interference of bias in decisions regarding performance and evaluation (Haefele, 1992). On the condition that the performance evaluation has a lengthy duration, the management can better understand teachers in this process. This situation was found to increase the teachers' performance, too.

Another finding was that TP could be promoted through efficient teacher training. Many articles about Finland's "secret" describe the revision of teacher education through a series of reforms since the early 1990s. Finland trains all teachers in three-year graduate programs. Afterwards, it focuses on developing a reflective, questioning approach toward teaching and learning, including instructing the learners with special needs as well as encouraging the involvement in strong content development and pedagogical preparation within the education system (DarlingHammond, 2006). The pedagogical education that teachers receive in their professional development is also important. To cite an example, per Japanese law, novice teachers receive at least 20 day-long service training sessions in their early years, along with a 60-day professional development in subjects such as classroom management and computer literacy (Darling-Hammond, 2005).

\section{Theme II: Process functioning}

Under this theme, the participants indicated the necessity of setting valid and reliable evaluation criteria. This finding was found to be similar to the results of the study carried out by Milanowski and Heneman (2001). The researchers of the study aimed to develop teacher assessment standards. In this context, the evaluation of a teacher's performance and the degree of that performance - under such titles as planning and preparation for students' learning, creating a learning environment, professionalism for teaching and learning - can provide information about the teacher's overall performance. When teachers are aware that they are being evaluated, they are more careful. On the other hand, teachers' belief that the more they contribute, the more benefits they get emphasizes the positive outcome of rewarding. This result is similar to the results in the literature that indicate such variables as attitude toward complementary processes, distinct administrator and teacher roles, goal-setting, and the use of alternative sources of information ensures quality education together with quality performance measurement (McGreal, 1982). Also, another result of the study was that evaluations which do not reflect the realms of the related processes and which refer to emotional decisions in the application of the assessment criteria should be avoided. This result may cause teachers to think that they are not trusted.

Reducing teachers' course load, joining in-school training with "designated guidance teachers" twice a week, and taking part in out-of-school training each week can be a good start. Additionally giving free time to senior teachers to guide novices may be one of the most important measures to increase the number of qualified teachers (Darling-Hammond, 2005). The evaluation of the teacher by an experienced and different eye was found to be important and beneficial for both the professional development and the personal development of the teacher. However, there are the opinions about the evaluation of newly recruited teachers with a different set of criteria. The contribution to the development of novice teachers can positively affect their performance.

\section{Theme III: Effect}

The data under this theme indicated that business anxiety, stress, and evaluation were feedback tools. Through TPE, teachers clearly understand their deficiencies or mistakes, what 
they should not do or what they do correctly, and how they would sustain the continuity of the correct behaviors. However, school administrators stated that feedback would be meaningful if it was holistic within the integrity of the system. In this context, the implementation of any school policy, including a teacher assessment policy, represents a continuous interaction among the various policy objectives, established rules, and procedures. To give an example, in an institutional context, teacher assessment procedures have the same effect at the school level as the political climate that exists in a school system, the relationship between teachers' organizations and district administration, the quality of other educational policies and business programs in the district, and bureaucratic processes such as the size and structure of the system (Darling-Hammond, Wise \& Pease, 1983). Besides concerns about pleasing the stakeholders in private schools can wear out people. Conducting a performance evaluation and renewing contracts every year makes sense in terms of administration and school operations. According to the study findings, TPE should be conducted by protecting the personal and social rights of teachers and without causing them to experience business anxiety.

\section{General Overview}

Nearly half of the participants expressed negative opinions about TPE under stakeholder opinion, setting criteria, emotional behavior, power battle, biased evaluation, business anxiety, and anxiety of satisfaction. The issues resulting in mobbing and threatening the teacher about non-renewal of their contract at the end of the year would both decrease TP. This was mentioned through the opinions expressed at the beginning of these codes. The finding that perceived control objectives are related to stress shows that communication of the very purpose of teacher assessment is still needed. Furthermore, the use of such plans tends to affect teachers' perceptions of their goals over time (Lejonberg, Elstad \& Christophersen, 2018). The conclusion that the present study reached is supported by the finding in the literature that teachers' stress and anxiety about their future, which they experience during the evaluation stage, negatively affects their efficiency.

Assessing teachers' performance is an important task. To make the evaluation process effective, the following general overviews can be considered: (1) Choose methods appropriate to the purpose of the evaluation; (2) Involve teachers in the evaluation; (3) Provide the relevant training; (4) Increase the sources of evaluation data; (5) Use meaningful criteria; and (6) Associate the outcomes with institutional objectives (Stiggins \& Bridgeford, 1985). When the general results were considered, the opinions that some of the features of TPE were not applied theoretically were in line with the research findings. In general, it was found that if the school manager carries out the assessment in a threatening manner and raises concerns about the teacher becoming unemployed, the teacher's feelings of suppression come to the fore.

\section{Suggestions}

In the education system, especially at tertiary level, the awareness of TP to stimulate changes of significant sort for a teacher should be raised. This awareness needs to be built on the fact that TPE provides an opportunity to revisit salient issues for the individual and for quality of education. TPE should be a system that can be checked as a guideline instead of an audit. In this context, teacher candidates' experiencing with the TPE evaluation system within the scope of a course may increase the quality of human resources. Nonetheless prior to the implementation of the education system by constructing the TPE system within the understanding of a common system, these contents can be guided.

On the other hand, one of the results highlighted in the research findings is the problem of 
business anxiety experienced by private school teachers. Even though it seems difficult to standardize things depending on what is expected from TPE, the evaluation of teachers within the system can be managed with standard measurement tools at first glance. Thereupon the fact that schools provide information about the human resources can play a role in increasing TP as well as reducing this anxiety. Accordingly, the results of TP have a function of presenting a source of information about the professional and pedagogical development of teachers. School principals should not use the results of TPE to place psychological pressure on teachers at the beginning of a term by focusing primarily on this function of it. Teacher monitoring may be spread out over a year with long repetitive and periodic measurements.

Moreover a platform can be established for private school teachers to find jobs under government supervision. For practitioners, these data serve as a reference for identifying primary problem areas in the development of teacher capacity. In general, policymakers may have the opportunity to use them during the policy design phase. Therefore, a nationwide teacher performance assessment model proposal is more than necessary.

The contract renewal criterion can be set apart from the TPE process, and it can be carried out by the human resources department in private schools. Therefore, evaluation of teacher efficiency may be done separately using other variables because the measurement of teacher effectiveness is a separate problem area and a phenomenon that would be wrong to handle in one-off cases.

\section{Strengths and Limitations}

The fact that this study consulted not only teachers or school management but also all stakeholders responsible for TP shows that the study has considerable strength. In qualitative analysis, analyzing the views according to the theoretical framework can sometimes be difficult. The analysis of the views in accordance with the theoretical framework of TPE in the literature has made it possible to systematize the prominent views based on the theoretical discipline. The diversity of views enabled us to reach feasible concrete recommendations. TP is associated with both in-school and out-of-school variables. Therefore, collecting the views of family and students and even in-school personnel within the study group may increase the scope of the criteria that are important for improving TP. However, in this study, the opinions of the parties responsible for determining TP were the focus of primary discussion. In this regard, a limitation of the study is that the boundaries of the sources of views could not be extended to in-school and out-of-school stakeholders. The frequency of the third theme of the study, the effect, was higher than the other themes. This is not something to do with the quality of the interviews, but private school teachers tend to focus on the negative situations such as unemployment, falling salary, provided TP is low. This may a limitation on account of the pragmatist ideas of the teachers, yet not interfering with the quality of the process. Another limitation of this study is that it was carried out in a single private school located in Turkey. The generalizability of the findings and results obtained within the scope of the study should be interpreted carefully by considering the necessary factors, including primarily cultural factors i.e. the context in particular.

\section{References}

Berlak, A. (2011). Can standardized teacher performance assessment identify highly qualified teachers?. Counterpoints, 402, 51-62.

Bogdan, R., \& Biklen, S. K. (1997). Qualitative research for education. Boston, MA: Allyn \& Bacon. 
Briggs, D., \& Domingue, B. (2011). A review of the value-added analysis underlying the effectiveness rankings of Los Angeles Unified School District teachers by the Los Angeles Times. Boulder, CO: National Education Policy Center.

Cohen, J., \& Goldhaber, D. (2016). Building a more complete understanding of teacher evaluation using classroom observations. Educational Researcher, 45(6), 378-387.

Coloma, R. S. (2015). Students are once again numbers instead of actual human beings: teacher performance assessment and the governing of curriculum and teacher education. Journal of the Canadian Association for Curriculum Studies, 13(1), 5-35.

Darling-Hammond, L. (2005). Teaching as a profession: Lessons in teacher preparation and professional development. Phi delta kappan, 87(3), 237-240.

Darling-Hammond, L. (2006). Securing the right to learn: Policy and practice for powerful teaching and learning. Educational Researcher, 35(7), 13-24.

Darling-Hammond, L. (2010). Evaluating teacher effectiveness: How teacher performance assessments can measure and improve teaching. USA: Center for American Progress. https://files.eric.ed.gov/fulltext/ED535859.pdf

Darling-Hammond, L. (2012). The right start: Creating a strong foundation for the teaching career. Phi Delta Kappan, 94(3), 8-13.

Darling-Hammond, L. (2015). Can value added add value to teacher evaluation?. Educational Researcher, 44(2), 132-137.

Darling-Hammond, L., Amrein-Beardsley, A., Haertel, E., \& Rothstein, J. (2012). Evaluating teacher evaluation. Phi Delta Kappan, 93(6), 8-15.

Darling-Hammond, L., Wise, A. E., \& Pease, S. R. (1983). Teacher evaluation in the organizational context: A review of the literature. Review of educational research, 53(3), 285-328.

Davey, B. (1991). Evaluating teacher competence through the use of performance assessment tasks: An overview. Journal of personnel evaluation in education, 5(2), 121-132.

Donaldson, M. L., \& Woulfin, S. (2018). From tinkering to going "rogue": How principals use agency when enacting new teacher evaluation systems. Educational Evaluation and Policy Analysis, 40(4), 531-556.

Ellett, C. D., Wren, C. Y., Callender, K. E., Loup, K. S. \& Liu, X. (1996). Looking Backwards with the" Personnel Evaluation Standards": An Analysis of the Development and Implementation of a Statewide Teacher Assessment Program. Studies in Educational Evaluation, 22(1), 79-113.

Epstein, J. L. (1985). A question of merit: Principals' and parents' evaluations of teachers. Educational Researcher, 14(7), 3-10.

Ghamrawi, N. (2010). No teacher left behind: Subject leadership that promotes teacher leadership. Educational Management Administration \& Leadership, 38(3), 304-320.

Haefele, D. L. (1992). Evaluating teachers: An alternative model. Journal of Personnel Evaluation in Education, 5(4), 335-345.

Harvey, L. (2002). Evaluation for what?. Teaching in Higher Education, 7(3), 245-263.

Hatipoğlu, A., \& Kavas, E. (2016). Veli yaklaşımlarının öğretmen performansına etkisi. Insan ve Toplum Bilimleri Araştırmaları Dergisi, 5(4), 1012-1034.

Herbert, J., \& Mcnergney, R. (1989). Evaluating teacher evaluators using a set of public standards. Journal of Personnel Evaluation in Education, 2(4), 321-333.

Kitsantas, A., \& Baylor, A. (2001). The impact of the instructional planning self-reflective tool on preservice teacher performance, disposition, and self-efficacy beliefs regarding systematic instructional planning. Educational Technology Research and Development, 49(4), 97-106. 
Lejonberg, E., Elstad, E., \& Christophersen, K. A. (2018). Teaching evaluation: antecedents of teachers' perceived usefulness of follow-up sessions and perceived stress related to the evaluation process. Teachers and Teaching, 24(3), 281-296.

Loup, K. S., Garland, J. S., Ellett, C. D., \& Rugutt, J. K. (1996). Ten years later: Findings from a replication of a study of teacher evaluation practices in our 100 largest school districts. Journal of Personnel Evaluation in Education, 10(3), 203-226.

Mason, J. (2002). Qualitative researching. London: Sage.

McGreal, T. L. (1982). Effective Teacher Evaluation Systems. Educational Leadership, 39(4), 303-5.

Milanowski, A. T., \& Heneman, H. G. (2001). Assessment of teacher reactions to a standardsbased teacher evaluation system: A pilot study. Journal of Personnel Evaluation in Education, 15(3), 193-212.

Miles, M., B. \& Huberman, A., M. (1994). Qualitative data analysis: An expanded sourcebook. (Second Edition). New York: Sage.

Mintrop, R., Ordenes, M., Coghlan, E., Pryor, L., \& Madero, C. (2018). Teacher evaluation, pay for performance, and learning around instruction: between dissonant incentives and resonant procedures. Educational Administration Quarterly, 54(1), 3-46.

Murphy, J. (1987). Teacher evaluation: A comprehensive framework for supervisors. Journal of Personnel Evaluation in Education, 1(2), 157-180.

Painter, S. R. (2000). Principals' efficacy beliefs about teacher evaluation. Journal of Educational Administration, 38(4), 368-378.

Peck, C. A., Gallucci, C., \& Sloan, T. (2010). Negotiating implementation of high-stakes performance assessment policies in teacher education: From compliance to inquiry. Journal of Teacher Education, 61(5), 451-463.

Peck, C. A., Singer-Gabella, M., Sloan, T., \& Lin, S. (2014). Driving blind: Why we need standardized performance assessment in teacher education. Journal of Curriculum and Instruction, 8(1), 8-30.

Peterson, K. D. (1989). Parent surveys for school teacher evaluation. Journal of Personnel evaluation in Education, 2(3), 239-249.

Peterson, K. D., \& Stevens, D. (1988). Student reports for school teacher evaluation. Journal of Personnel Evaluation in Education, 2(1), 19-31.

Peterson, P. L., \& Comeaux, M. A. (1990). Evaluating the systems: Teachers' perspectives on teacher evaluation. Educational Evaluation and Policy Analysis, 12(1), 3-24.

Qi, Y., Bell, C. A., Jones, N. D., Lewis, J. M., Witherspoon, M. W., \& Redash, A. (2018). Administrators' Uses of Teacher Observation Protocol in Different Rating Contexts. ETS Research Report Series, 2018(1), 1-19.

Reid, D. B. (2019). What information do principals consider when evaluating teachers?. School Leadership \& Management, 1-21.

Richardson, J., T., E. (1999). The concepts and methods of phenomenographic research. Review of Educational Research, 69(1), 53-82.

Ross, D. E., Singer-Dudek, J., \& Greer, R. D. (2005). The teacher performance rate and accuracy scale (TPRA): Training as evaluation. Education and Training in Developmental Disabilities, 40(4), 411-423.

Saldaña, J. (2015). The coding manual for qualitative researchers. London: Sage.

Shulman, L. (1987). Knowledge and teaching: Foundations of the new reform. Harvard educational review, 57(1), 1-23.

Stiggins, R. J., \& Bridgeford, N. J. (1985). Performance assessment for teacher development. Educational Evaluation and Policy Analysis, 7(1), 85-97. 
Şahin, F., Sönmez, E., \& Yavuz Tabak, B. (2019). A variable predicting school climate: the personality traits of school principals. Başkent University Journal of Education, 6(2), 202-212.

Şat, A. (2013The Views on The Practices of Performance-Based Supervision of The Teachers at Educational Organi-zation: The Private School Sample. OPUS-International Journal of Society Researches, 3(5), 49-66.

Taylor, E. S., \& Tyler, J. H. (2012). The effect of evaluation on teacher performance. American Economic Review, 102(7), 3628-51.

Tschannen-Moran, M., Hoy, A. W., \& Hoy, W. K. (1998). Teacher efficacy: Its meaning and measure. Review of educational research, 68(2), 202-248.

Tuytens, M., \& Devos, G. (2014). How to activate teachers through teacher evaluation?. School effectiveness and school improvement, 25(4), 509-530.

Wilson, B., \& Wood, J. A. (1996). Teacher evaluation: A national dilemma. Journal of Personnel Evaluation in Education, 10(1), 75-82.

Yildırım, A. (2013). Teacher Education Research in Turkey: Trends, Issues and Priority Areas. Education \& Science, 38(169), 175-191.

Yıldırım, A. ve Şimşek, H. (2008). Sosyal bilimlerde nitel araştırma yöntemleri [Qualitative research methods in Social Sciences $]$. ( $7^{\text {th }}$ edition). Ankara: Seçkin. 